\title{
Os jogos de linguagem no discurso infantil: implicações na constituição do letramento oral
}

\section{Language games in child's speech: implications for the development of oral literacy}

Neilson Alves de Medeiros*

Instituto Federal de Educação, Ciência e Tecnologia da Paraíba

João Pessoa- Paraíba / Brasil

RESUMO: O presente trabalho objetiva discutir o papel que os jogos de linguagem possuem no desenvolvimento de gêneros textuais orais, também responsáveis pela inserção da criança em práticas letradas. Para tanto, discutiremos as noções de jogos de linguagem e de gêneros textuais, buscando identificar nesses fenômenos as diversas vias de acesso ao letramento como processo multidimensional. Com isso, adotaremos uma investigação de cunho interpretativista, observando dados referentes a um corpus coletado em sala de aula da Educação Infantil, com crianças na faixa etária de quatro anos de idade. Nossos resultados apontam a presença de jogos de linguagem nos gêneros orais que se apresentam em sala de aula. Isso nos leva a crer que as práticas letradas demandam o uso de jogos de linguagem, uma vez que eles viabilizam a diversidade de formas de utilização da língua.

PALAVRAS-CHAVE: jogos de linguagem, gêneros orais, letramento.

ABSTRACT: This paper aims to discuss the role that language games play in the development of oral textual genres, which could also guide the insertion of child into literacy practices. In order to do that, we will discuss the concept of language games, textual genres and genre systems, trying to identify, in these phenomena, the various ways to access literacy as a multidimensional process. Thus, we adopt a qualitative approach, observing data from a corpus obtained in a kindergarten classroom, with children aged 4 years old. Results highlight the existence of language games in oral textual genres in the classroom situations. It implies that literacy practices demand the use of language games, for they allow diversity of forms to use language.

KEYWORDS: language games, oral textual genres, literacy.

*neilsonmedeiros@yahoo.com.br.

Doutorando do PROLING/UFPB. 


\section{Introdução}

Esse trabalho visa discutir o papel que os jogos de linguagem possuem no desenvolvimento de gêneros textuais orais, responsáveis pela inserção da criança em práticas letradas. Buscamos discutir questōes referentes à noção de jogos de linguagem, letramento e gêneros orais. Para tanto, discorreremos sobre alguns posicionamentos que passam pela Filosofia da Linguagem, pela Linguística Textual e pela Aquisição da Linguagem.

$\mathrm{Na}$ segunda parte de nosso trabalho, exporemos questôes que concernem à metodologia utilizada em nossa investigação. A terceira parte, por sua vez, tratará de uma análise de produçóes orais de alunos com idade em torno de quatro anos, com participação de adultos (professora e estagiária).

Esperamos que nosso trabalho possa servir a outras reflexóes na compreensão dos fenômenos estudados.

\section{Aporte teórico}

\subsection{Por uma noção de letramento oral}

De modo a alicerçar nosso trabalho, discutiremos algumas questôes relacionadas, sobretudo, à noção de jogos de linguagem e de gêneros discursivos, observando esses fenômenos com vistas a compreender a constituição do letramento.

Antes disso, é necessário pontuar nossa concepção de letramento. Discutida por vários autores (SOARES, 2001; ROJO, 2001; MARCUSCHI, 2001b), o termo "letramento" sofreu várias revisōes, tendo como princípio básico os usos sociais que fazemos da leitura e da escrita.

Segundo Soares (2001), esse fenômeno, inicialmente, dizia respeito à capacidade individual de ler e escrever, confundindo-se com alfabetização, uma vez que a palavra inglesa literacy pode designar letramento ou alfabetização. Para Graff (1979), por exemplo, letramento consiste na habilidade de codificar ou decodificar materiais escritos e impressos. Percebe-se que tal afirmação ainda não contempla os usos sociais da leitura e da escrita.

Na acepção do letramento trazida por Graff (1979), podemos perceber ainda uma visão subjacente de língua como instrumento de comunicação, cuja prioridade está no código. Dessa maneira, para que uma prática de letramento fosse concretizada, seria necessário haver a ativação de processos linguísticos e mentais, obscurecendo os fatores sociais nessas práticas. 
Opondo-se à perspectiva individual do letramento, Scribner (apud MARCUSCHI, 2001b) define esse fenômeno como uma transmissão cultural, regida pelos fatores sociais. Dessa maneira, sob essa ótica, letramento caracteriza-se como aquilo que as pessoas fazem com a leitura e a escrita, ou seja, que funcionamentos são conferidos à leitura e à escrita, tendo o contexto e seus sujeitos implicados no processo.

Ao atribuir o caráter social ao letramento, exclui-se a equivalência entre indivíduo letrado e indivíduo alfabetizado. A não apropriação do código escrito de uma língua por um indivíduo não impede que práticas de letramento sejam efetuadas por ele. Uma pessoa sem escolaridade, por exemplo, inserida em rotinas que demandam o uso de ônibus, pode ser capaz de distinguir, por meio de sinais gráficos, o veículo adequado para seu objetivo.

Por outro lado, alguém que saiba ler e escrever pode encontrar dificuldades na compreensão de textos técnicos de uma área de conhecimento restrita. Portanto, como sujeitos sociais, capazes de circular por diversos domínios, deparamo-nos com diferentes maneiras de lidar com os usos da leitura e da escrita, o que daria margem para o conceito de múltiplos letramentos que, de acordo com Street (1995, p. 2), surgem em consonância com os diversos contextos sociais e culturais nos vários grupos sociais existentes, ganhando destaque os usos da língua na relação entre os atores sociais e os eventos socioculturais dos quais fazem parte.

$\mathrm{Na}$ vertente social de letramento, podemos ainda encontrar duas correntes que se posicionam de forma "fraca" ou "forte". A primeira, como colocam Soares (2001) e Marcuschi (2001a), seria um letramento funcional, em que o sujeito recorre a um conjunto de habilidades associadas à leitura è̀ escrita, de modo que possa atender a exigências sociais. Para essa perspectiva, o letramento resulta no desenvolvimento do indivíduo como um todo, culminando no sucesso pessoal e na mobilidade social.

Diferenciando-se da vertente "fraca", encontramos uma versão "forte" do letramento social, que preconiza a inexistência do letramento como instrumento neutro a ser utilizado nas práticas sociais quando exigido. Tratase de um conjunto de práticas socialmente construídas, envolvendo a leitura e a escrita e estando sob a influência de processos sociais mais amplos. Esse modelo, chamado de ideológico por Street (1984), reforça a ideia de que o letramento não consiste em um conjunto de práticas universais, mas sofre mudanças conforme a comunidade onde se instaura. 
No modelo ideológico do letramento social, as relações de poder são reforçadas ou enfraquecidas, servindo de espaço para uma dinâmica nas práticas do uso da escrita e da leitura. Essa dinâmica, para Street (1984), revela a distinção entre evento de letramento e prática de letramento, em que a primeira se manifesta nas ocasiōes em que uma peça escrita integra a natureza das interações dos participantes e seus processos interpretativos. Já a prática de letramento tem a ver com modos culturais gerais de uso da escrita e da leitura, as quais produzem eventos de letramento. Um exemplo que elucida essa diferença seria o gênero carta pessoal. Sua ocorrência remeteria a um evento de letramento, que desencadeia comentários entre membros de uma família sobre essa prática, gerando uma prática de letramento.

Cabe, nesse contexto, voltar nosso olhar para o que designamos aqui de letramento oral. Segundo Terzi (1995), ao chegar à escola, a criança geralmente apresenta um bom domínio da modalidade oral da língua. Esse repertório já presente serve como base para a constituição da modalidade escrita, correspondendo, assim, ao modelo proposto por Kato (1986):

$$
\text { fala } 1 \rightarrow \text { escrita } 1 \rightarrow \text { escrita } 2 \rightarrow \text { fala } 2
$$

O esquema evidencia etapas de desenvolvimento da linguagem, que passam por uma fala 1 , sem influências da escrita e da leitura, que dá sequência para a aquisição de uma escrita 1 , cuja função consiste muito mais em reproduzir a fala. A partir daí, a escrita se tornaria mais complexa e influenciaria a fala, determinando a emergência da escrita 2 e da fala 2 . Esse esquema condiz com a discussão proposta por Bakhtin (1991) acerca dos gêneros primários e secundários, já que aqueles compreenderiam as conversas espontâneas, por exemplo, sendo responsáveis pela constituição de outros gêneros considerados mais complexos, como uma exposição oral, por exemplo.

Terzi (1995) organiza o esquema elaborado por Kato, extrapolando a linearidade da transição entre as etapas, culminando no seguinte modelo:

$$
\text { fala } 1 \rightarrow \text { escrita } 1 \rightarrow \text { fala } 2 \rightarrow \text { escrita } 2
$$

A reformulação do modelo compreende uma relação dialética entre fala e escrita, em que uma antecede a outra de maneira cronológica apenas. Em termos de funcionamento, o discurso da criança, mesmo não alfabetizada, possui em sua organização aspectos referentes ao letramento e à oralidade. Dessa maneira, poderíamos levantar a hipótese de que a fala da criança, mesmo sem muito contato com as práticas diretamente fundadas na escrita, constrói-se em 
meio a um conjunto de textos, orais e escritos, que pertencem às situações por onde as crianças circulam. Assim, poderíamos arriscar uma definição de letramento oral como conjunto de práticas que, mesmo materializadas na modalidade oral da língua, reflete movimentos que dizem respeito ao funcionamento de textos escritos, uma vez que não se produz linguagem de modo isento aos diversos textos que circulam no cotidiano da criança. Essa relação não se daria de maneira única e unilateral, mas poderia variar conforme as peculiaridades que envolvem a história de cada sujeito. Um exemplo desse conjunto de práticas ocorre no ambiente da sala de aula, onde os alunos conversam, expóem, debatem, apresentam seminários, realizando essas tarefas por meio de gêneros orais que, dentro do universo escolar, cruzam com gêneros escritos, como roteiros, livros, fichas de avaliação. Além dessa proximidade com a escrita, as práticas do oral na sala de aula põem em cena outros papéis para os interlocutores: o filho passa a ser aluno; o adulto não consiste em um familiar, mas no professor. Em cada esfera social, seria possível pensar em diferentes características do que denominamos aqui como letramento oral.

Entretanto, ao assumir a perspectiva de uma fala letrada desde os primeiros anos da criança, devemos estabelecer, segundo análises de textos orais de crianças, alguns mecanismos que podem ou não evidenciar o processo falaescrita como dialético. Diante disso, partiremos da noção de jogos de linguagem, buscando compreender essa atividade como constitutiva das práticas letradas na fala.

\subsection{Jogos de linguagem: gêneros em estabilização?}

O conceito de gêneros textuais, assim como o de letramento, desdobrase em uma série de perspectivas que enfatizam principalmente seu caráter sociocomunicativo e histórico. Apesar da imensidão de contribuições, trazemos aqui Bakhtin (1991), por nos fornecer a definição mais emblemática de gênero como constituído por enunciados relativamente estáveis, sendo por nós utilizados para o cumprimento de alguma tarefa.

Sublinhamos, para nosso interesse, a expressão estáveis, pois seria nesse ponto que os jogos de linguagem cumpririam seu papel na aquisição da linguagem. Isso significa que, para aprender a linguagem, a criança se engaja em interações dos mais diversos tipos, passando a manejar diversos gêneros. No entanto, até estabilizar para si os usos historicamente consolidados da linguagem, a criança passaria por instâncias mais fugidias, porém, extremamente férteis, que podem ser denominadas jogos de linguagem. 
Wittgenstein (1999), ao optar por uma perspectiva que contempla o uso da linguagem, trata a aquisição como um ensino ostensivo da língua, em que a criança é submetida a um treinamento orientado pelo funcionamento dos enunciados (frases). Muito embora nomear a aquisição da linguagem como um treinamento seja algo incompatível com a perspectiva sociointeracionista, existiria aí uma aproximação quando o uso é realçado. $\mathrm{O}$ autor, portanto, afirma o seguinte sobre jogos de linguagem:

(...) jogos por meio dos quais as crianças aprendem sua língua materna. (...) E poder-se-iam chamar também de jogos de linguagem os processos de denominação das pedras e da repetição da palavra pronunciada. Pense os vários usos das palavras ao se brincar de roda. (WITTGENSTEIN, 1999, p. 30).

É evidente, segundo o trecho citado, que o autor atribui uma função primordial aos jogos de linguagem na aquisição da linguagem, abrangendo, por exemplo, o ato de nomear objetos, passando pela repetição/retomada de enunciados até a criatividade presente nas brincadeiras.

Seguindo ainda o pensamento de Wittgenstein (1999), reconhecemos o grande alcance e diversidade que os jogos de linguagem atingem, uma vez que a criança, desde os primeiros anos de vida, assume um papel ativo nas interações, chegando à escola já com a capacidade de conversar, brincar e nomear objetos ou situações.

Para elucidar como funcionam os jogos de linguagem, Wittgenstein (1999) compara a linguagem a uma caixa de ferramentas, em que os objetos possuem semelhanças e diferenças entre si. As diferenças, nesse caso, são dadas muito mais em decorrência dos usos que vinculamos aos instrumentos, o que acentua o caráter social do fenômeno.

Rojo (2010) retoma a ideia de jogos de linguagem de Wittgenstein, elegendo os gêneros do discurso como unidades de análise, argumentando que essas entidades dão conta do processo de construção social da fala e da escrita. Nessa construção, segundo Rojo (2010), em fase inicial da aquisição da linguagem, figuram os jogos de linguagem como açôes puras, ou seja, ainda isentas dos efeitos do discurso. Açôes que, segundo Rojo (2010), mesmo sendo interpretadas discursivamente pelo outro (adulto, geralmente), ainda são ações. Nisso, teríamos a criança envolvida em atividades constituídas pelos gêneros, já que desde cedo ela conversa, ouve e conta histórias e relata eventos, por exemplo. No entanto, tais gêneros não surgem prontos, mas passam por 
interações mais elementares, em que a criança não possui muita autonomia na produção discursiva, tendo geralmente o adulto como parceiro nesse percurso.

Os jogos de linguagem, portanto, prestam-se a viabilizar a transição das ações para os gêneros primários e, consequentemente, para os secundários. Nesse percurso, como lembra Rojo (2010, p. 49):

(...) alguns desses jogos se apresentam como ordem/obediência; pergunta/réplica, no diálogo familiar (dando base para os gêneros primários); outros voltam-se para outras construções linguísticas, como a da nomeação ou a da frase, e, feito isso, desaparecem transmutados em outros jogos mais próximos da construção de gêneros já secundários (como o jogo de contar, que vai (re)constituir os contos de fadas e histórias infantis); outros ainda desaparecem sem deixar traços.

Surgem, na discussão de Rojo, algumas questões que fogem à nossa perspectiva. Trata-se da configuração linear que a autora confere ao desenvolvimento da linguagem. Concordamos com o princípio de construção social da linguagem, mas buscamos nos distanciar de uma construção homogênea, em que a criança completaria uma série de etapas que, indiretamente, rotulam fala e escrita / gêneros primários e gêneros secundários como simples e complexas. Diferentemente do que é posto pela autora, entendemos as modalidades e os gêneros como dialéticos, ou seja, fenômenos que se influenciam mutuamente desde sua emergência.

Ainda sobre a pesquisa empreendida por Rojo (2010), vale mencionar os jogos de linguagem que a autora tentou reunir em um modelo de análise. Wittgenstein (1999) não se preocupa, em seu texto, com uma identificação precisa dos tipos de jogos. Vejamos a seguir um esquema, presente em Rojo (2010), que resume os jogos:

AL teleológica $>$ jogos de linguagem

1. Jogo de ordenar (fazer fazer

2. jogo de papéis (fazer fazer como se)

3. jogo de nomear (fazer falar-nomear)

4. jogo de contar (fazer falar - contar)

AL normativa $>$ jogos de linguagem

1. Jogos deônticos (poder/deixar fazer)

2. jogos epistêmicos (não) saber fazer)

A classificação dada surge de dois grandes grupos de atividade de linguagem (AL): teleológica (voltada para ações com uma finalidade imediata) e normativa (que visa regular o comportamento ou conhecimento sobre uma 
ação). Os dois grupos dividem-se, por sua vez, em seis tipos: jogos de ordenar, jogos de papéis, jogos de nomear, jogos de contar, jogos deônticos e jogos epistêmicos.

Acreditamos que o modelo em questão favorece nossa análise, possibilitando verificar como esses jogos atuam não apenas na fase mais tenra da aquisição da linguagem, como também na construção de outros gêneros, como o gênero oral "regras de jogo", em um momento de ingresso da criança na vida escolar. Portanto, retomaremos essa questão em nossas análises.

Levando em conta a interface que nosso trabalho estabelece com a Aquisição da Linguagem, traremos aqui as contribuiçōes de Bruner (1975) a respeito da organização do discurso infantil. Para esse autor, o êxito da criança em atingir a ação conjunta (ou o êxito da mãe) virtualmente a direciona para a linguagem. Nesse sentido, dominar o sentido do enunciado - eficácia ou felicidade na conquista de um objetivo - provê a criança com a estrutura conceptual que é "encarnada" na língua que ela aprende. Isso implica dizer que muito do que se aprende no que concerne à língua compreende um reflexo dos esquemas construídos na ação conjunta. Estudos sobre relações semânticas em algumas línguas (BOWERMAN, 1970 apud BRUNER, 1975), por exemplo, correspondem a determinadas estruturas: Agente - ação (mamãe empurrar); Ação - objeto (morder dedo); Posse (carro da tia); Marcador demonstrativo (aquela vaca); Marcador de traço (cama grande).

No que tange ao que o autor denomina de jogos, podemos encontrar neles a função de levar a atenção da criança para a comunicação em si e para a estrutura dos atos em que a comunicação toma lugar. A importância do jogo não estaria naquilo que é feito nele, mas em comóé feito. Na brincadeira, o comportamento está desacoplado de suas consequências normais. Nisso entram a flexibilidade e a frivolidade. A brincadeira permite que a criança varie na ordem de combinar açôes e sinais. Nesse ponto, as interpretaçôes da mãe sobre os sentidos intencionados pela criança são de suma importância, pois confirmam as hipóteses levantadas pela criança. Daí o papel crucial do outro (no caso, o adulto) na condução e possível estabilização desses jogos, o que sanciona o acesso às práticas letradas.

Por fim, os autores com os quais dialogamos enfatizam o papel do jogo como espaço de desenvolvimento da linguagem, abrigando processos que desaparecem ou se firmam ao longo da história dos sujeitos, mas que permanecem, de um modo ou de outro, como mecanismos de aprendizagem dos gêneros do discurso. 


\section{Metodologia}

Nosso trabalho vale-se de uma breve análise que não se propõe ser exaustiva. Utilizamos dados referentes a um corpus coletado em uma turma da Educação Infantil, com alunos na faixa etária de quatro anos de idade.

Os registros se deram com a utilização de uma câmera digital, em cinco sessões distribuídas em dois meses. As sessões correspondem às aulas em que a professora desenvolvia uma sequência didática ${ }^{1}$ cujo objetivo consistia na aprendizagem do gênero oral "regras de jogo".

O corpus, coletado para uma pesquisa de mestrado que se debruçava sobre a organização da textualidade no gênero "regras de jogo", é retomado com outros objetivos.

Nosso critério para seleção dos dados ora discutidos limita-se à presença dos jogos de linguagem de maneira mais explícita, tanto no discurso das crianças quanto nas produçóes da professora e da estagiária da sala, o que nos inclui na abordagem de análise interpretativista.

Com isso, ressaltamos o funcionamento dos jogos de linguagem na construção das práticas letradas na oralidade em uma sala de aula da Educação Infantil, tendo como base o percurso para aquisição do gênero "regras de jogo".

\section{Jogos de linguagem: uma análise das produções orais de crianças em situação escolar}

O primeiro trecho que trazemos diz respeito ao momento em que a professora, buscando situar as crianças na atividade que se inicia, pergunta sobre as brincadeiras favoritas dos alunos. Nesse momento, podemos verificar o papel do adulto na dinâmica dos jogos de linguagem, tendo a função de mediar e gerir o discurso no espaço da sala de aula:

\footnotetext{
${ }^{1}$ Para uma melhor compreensão de sequência didática, recomendamos a leitura de SCHNEUWLY, Bernard; DOLZ, Joaquim. Gêneros orais e escritos na escola. Campinas, SP: Mercado de Letras, 2004.
} 


\section{QUADRO 1}

Análise da produção oral - trecho 1

\begin{tabular}{|l|l|}
\hline 13. Profa. & Qual a brincadeira que você mais gosta? \\
\hline 14. Carlos & De esconde-esconde (voz baixa) \\
\hline 15. Profa. & Ah, de esconde-esconde. E como é que brinca? \\
\hline 16. Eduarda & Você corre aí... \\
\hline 17. Profa. & E como é que brinca? \\
\hline 18. Carlos & (fala muito baixo, sendo incompreensível) \\
\hline 19. Profa. & Hâ? Aaah, com quem que você brinca de esconde-esconde? \\
\hline 20. Carlos & meu irmão \\
\hline
\end{tabular}

O fragmento corrobora a ideia de que o professor reveste-se do papel de tutor em relação aos alunos, dentro do ambiente escolar. Como espaço institucional, pressupomos que a sala de aula, mesmo na Educação Infantil, tende a orientar o discurso dos sujeitos que por ali transitam, aproximando a fala e a escrita a um registro formal e mais complexo da linguagem.

Essas práticas, fomentadas pelo uso de jogos de contar como "E como é que brinca?" (turno 17$)^{2}$ repartiriam a linguagem, ou seja, no universo imenso de possíveis realizações, as crianças são encaminhadas a elaborar discursos específicos vinculados a contextos específicos. Parece trivial imaginar isso sob o ponto de vista das produções discursivas de um adulto, mas para a criança se abre uma nova maneira de usar os instrumentos que a linguagem oferece.

Essas práticas, que são socialmente situadas, possuem a função de organizar o discurso oral: por exemplo, o aluno que explica como se brinca determinado jogo perante os colegas e a professora, que por sua vez encontramse dispostos em círculo, com objetivos mais ou menos discriminados pela docente. Esse conjunto que se manifesta, apesar da ausência do registro escrito, pode ser denominado de prática letrada, pois se inicia uma forte associação a finalidades sociais da linguagem, mesmo que isso seja frequente muito antes do ingresso na vida escolar. Vejamos um segundo momento, proveniente de outra sessão:

\footnotetext{
${ }^{2}$ Os números presentes nos quadros e utilizados nas análises referem-se aos turnos que cada interlocutor assume no corpus analisado.
} 
QUADRO 2

Análise da produção oral - trecho 2

\begin{tabular}{|l|l|}
\hline 227. Est & $\begin{array}{l}\text { Primeiro o Bruno então. A gente vai ficar, ó (fazendo gesto } \\
\text { de silêncio com o dedo nos lábios) }\end{array}$ \\
\hline 228. Profa. & Todo mundo prestando atenção qual a regra que o Bruno vai dizer. \\
\hline 229. Bruno & Quem pegá aí fica gelo ((?)) \\
\hline 230. Profa. & Fale direito! Assim bem bonitinho. \\
\hline
\end{tabular}

No contexto, a professora e a estagiária da sala pedem aos alunos para prestarem atenção à exposição de Bruno, além de pontuarem o modo como o aluno produz a exposição, como no turno 230. Poderíamos nomear esse movimento como um jogo deôntico, visto que há uma normatização das ações do grupo, partindo das autoridades da sala.

Novamente verificamos os jogos de linguagem sendo regidos pelos adultos, dando margem para que a criança se beneficie das funçóes que os gêneros fornecem. Na verdade, uma ressalva merece ser feita aqui: acreditamos que a presença de jogos de linguagem, em fases mais desenvolvidas da linguagem, não exclui a presença de gêneros discursivos.

Nisso, reforçamos que os jogos de linguagem, muito embora considerados como atividades linguageiras anteriores aos gêneros discursivos, ainda se apresentam em momentos mais tardios, talvez servindo como um mecanismo de aprendizagem de novos gêneros. No caso analisado, teríamos algo próximo ao gênero "exposição" por parte da estagiária e da professora, mas devido à dinâmica da oralidade, os formatos ainda são um pouco instáveis. Portanto, gêneros discursivos podem portar enunciados que se caracterizam como jogos e essa composição auxilia os usuários da língua na construção dos diversos gêneros que podem aprender.

O próximo texto, dessa vez produzido por uma das alunas, reivindica o uso de jogos de linguagem para as crianças também. Vejamos:

\section{QUADRO 3}

Análise da produção oral - trecho 3

\begin{tabular}{l|l}
244. Eduarda & $\begin{array}{l}\text { É, primeiro quando a gente chega, a pessoa tem que ficar sentada } \\
\text { um pedacinho para poder saber a regra. Aí depois começa a } \\
\text { brincadeira. Escolhe um pegador e escolhe a brincad/ aí vai, aí } \\
\text { começa a brincadeira. Aí... aí depois (.) aí depois quando é, depois } \\
\text { a pessoa fica descansando e continua a brincadeira. }\end{array}$
\end{tabular}


Em um momento mais avançado da sequência didática, a professora dá espaço para os alunos produzirem as "regras do jogo". A produção de Eduarda poderia ter outros formatos, mas com um conteúdo similar. Imaginemos a criança em questão conversando com uma colega de sala na hora do intervalo, sem ter passado pelas intervençōes da professora sobre como apresentar regras de um jogo. Provavelmente um jogo materializado pelo enunciado "a pessoa tem que ficar sentada um pedacinho para poder saber a regra" seria usado, já que a intenção aí vai pelo lado da regulação dos comportamentos.

Porém, possivelmente Eduarda seria interrompida por seus colegas, que poderiam se interpor ao seu discurso, lançando enunciados sobre as regras que eles pensariam no momento: alguns concordariam, outros complementariam a colega e outros discordariam, propondo outras ideias. $\mathrm{O}$ problema reside em como esses jogos, no caso, de natureza deôntica, evoluiriam para o gênero "conversa" ou para o gênero "exposição" ou ainda para "regras de jogo". ${ }^{3}$ Disso decorre que os jogos de linguagem, embora sejam estruturas ainda fugidias, são proveitosos no sentido de que possibilitam caminhos diversos para o usuário da língua percorrer.

Os jogos de linguagem, portanto, configuram a base para a aprendizagem de gêneros discursivos, estabilizando-se e aperfeiçoando-se frente ao mundo letrado. Além disso, seu funcionamento multifacetado permite que os jogos de linguagem estejam nas fronteiras entre os gêneros discursivos. No caso, tanto uma conversa mais solta quanto as regras de jogo possuem em seu interior enunciados deônticos. Sua intensidade e organização nos textos é que sofre alterações, de acordo com os traços de cada gênero. A palavra jogo implica relaçăo, funcionamento e, acima de tudo, possibilidades. Seriam os jogos de linguagem responsáveis, em parte, pelo grande alcance do letramento?

O terceiro trecho que trazemos para análise diz respeito à última etapa de produção das regras de jogo, em que os alunos apresentam as regras desenvolvidas para os colegas de outra turma.

\footnotetext{
${ }^{3}$ Talvez não seja consensual a distinção entre os gêneros "exposição oral" e "regras de jogo". Conferimos ao segundo uma estrutura composta, em sua grande parte, de tipos injuntivos, dando-lhe um contorno mais específico (antes das brincadeiras ou dos jogos) do que a exposição oral, que pode ser mais abrangente.
} 


\section{QUADRO 4}

Análise da produção oral - trecho 4

\begin{tabular}{|l|l|}
\hline 356. Profa. & $\begin{array}{l}\text { (para Eduarda em voz baixa) Olha pro tio Neilson e pros } \\
\text { coleguinhas. }\end{array}$ \\
\hline 357. Est. & Diga qual a brincadeira e explique. \\
\hline 358. Profa. & Qual é a brincadeira Eduarda? \\
\hline 359. Eduarda & $\begin{array}{l}\text { É a brincadeira pega-gelo. E essa brincadeira, escolhe um pegador } \\
\text { aí aí quando contar até três aí aí aí depois vai, corre (gesto circular } \\
\text { com o braço para cima) se um pegar o outro amiguinho (faz gesto } \\
\text { de agarrar com a mão) tem que ajudar e pegar (repete o gesto de } \\
\text { agarrar) e ajudar. }\end{array}$ \\
\hline 360. Profa. & O que mais? \\
\hline 361. Eduarda & (baixa a cabeça) \\
\hline 362. Profa. & Depois quando tiver cansado. \\
\hline 363. Eduarda & Depois quando tiver cansado vai descansar. \\
\hline 364. Profa. & E escolher \\
\hline 365. Eduarda & E escolher um pegador e continua a brincadeira. \\
\hline
\end{tabular}

Destaca-se, em primeiro lugar, o conjunto de gêneros que se colocam antes e após as regras de jogo. Tendemos a imaginar os gêneros como unidades separadas em gavetas etiquetadas. Mas nas interações concretas, a realidade se mostra bem heterogênea: os textos organizam-se dentro de conjuntos, que por sua vez, agregam-se, culminando em sistemas de gêneros. Bazerman (2006) propõe essa sistemática, mas se detém aos gêneros escritos e institucionalizados.

Poderíamos, por exemplo, afirmar que, para a elaboração bem sucedida de Eduarda, a professora e a estagiária tecem conversas ou orientaçóes que sustentam o seu texto. Ao indagar a aluna sobre o nome da brincadeira (linha 358), visando uma entrada da aluna no gênero a ser usado, temos o jogo de nomear. Somado a isso, a estagiária (linha 359) recorre ao jogo de ordenar, sinalizando ainda mais o procedimento que a aluna deveria assumir para produzir seu texto.

Um jogo de linguagem geralmente só se torna pleno quando temos um parceiro que replica, que o impulsiona. Eduarda nomeia a brincadeira e esforçase para explicar, demonstrando não apenas que conhece o funcionamento dessas atividades, mas que elas são úteis na sua produção textual. Outro indício que acentua o valor dos jogos de linguagem estaria, dentre outras coisas, na utilização de gestos por parte de Eduarda em seu texto: aí aí aí depois vai, corre (gesto circular com o barco para cima) se um pegar o outro amiguinho (faz 
gesto de agarrar com a mão) tem que ajudar e pegar (repete o gesto de agarrar) e ajudar. Além do verbo "ter" como recurso dos jogos deônticos, o gesto de agarrar a colega que se encontra ao seu lado demonstra que os jogos de linguagem não se restringem ao verbal, mas exploram outras modalidades. Ao referido gesto de agarrar, podemos atribuir os jogos de papéis, ou seja, mesmo fora da brincadeira, fingir que está brincando e agarrar o colega.

Certamente os colegas de Eduarda compreenderam as regras do jogo e perceberam que seu modo de falar não equivaleria a outras circunstâncias que se dão fora da sala de aula. A cena sobre a qual discorremos não apresenta interrupções por parte de outros alunos nem indiferença por parte da aluna em relação ao esforço de falar sob coordenadas socialmente estabelecidas. Se a linguagem se modifica e se isso ocorre principalmente por questôes sociais (uma tarefa proposta pela autoridade da sala de aula; estar disposto a ajudar os colegas da outra sala a compreender melhor a brincadeira "pega-gelo"; facilitar a gestão de brincadeiras junto aos colegas de sala e de escola), então podemos afirmar que essa fala já mantém em si o fenômeno do letramento escolar.

\section{Considerações finais}

Nosso trabalho discutiu a articulação entre jogos de linguagem, gêneros orais e letramento. Dentre as questóes apresentadas, salientamos mais uma vez que os jogos de linguagem não são fenômenos exclusivos da fase inicial de aquisição da linguagem, mas atravessam a história dos usuários da língua, fornecendo as bases para a manutenção de gêneros e aprendizagem de novos. Tal funcionamento reflete a importância que os jogos de linguagem possuem sobre a constituição do letramento escolar, uma vez que essas atividades aparentemente simples podem suscitar atividades mais complexas, com funcionamentos variados.

Outros pontos merecem ser retomados:

a) ao adquirir o gênero "regras de jogo", a criança passa por outros gêneros como "diálogo" e "exposição oral", o que dá suporte a uma noção de sistema de gêneros no discurso infantil;

b) Rojo (2010) afirma que os jogos de linguagem seriam as primeiras manifestações que, ao se estabilizarem, tornam-se gêneros. $\mathrm{Na}$ zona fronteiriça entre gêneros, sobretudo no continuum gêneros primários gêneros secundários, os jogos de linguagem são retomados e facilitariam o acesso da criança a formas mais complexas de linguagem; 
c) concebendo o letramento fundado nas atividades sociais de uso da língua, podemos compreender que os jogos de linguagem funcionam como mecanismos de mobilidade da criança dentro das diversas formas de letramento;

d) o papel do adulto (professor) na cogestão dos jogos de linguagem, que estabelece um eixo que sustenta a construção dos gêneros e viabiliza o acesso às diversas formas de letramento;

e) há evidências que apontam para a existência do letramento oral no contexto da Educação Infantil, em que a modalidade oral, mesmo que cronologicamente anterior à escrita, desdobra-se em vários formatos, sofrendo influências dos usos sociais da leitura e da escrita já consolidados.

Admitimos que essas conclusões não são definitivas e que o tema proposto precisa ser revisto mediante diálogos com outros pesquisadores interessados no assunto. Não podemos negligenciar uma oralidade enformada pela sociedade escriturística (DE CERTEAU, 1996) e que se organiza como um sistema dinâmico e complexo.

\section{Referências}

BAKHTIN, M. Estética da criação verbal. São Paulo: Martins Fontes, 1991.

BAZERMAN, C. Gêneros textuais, tipificação e interação. São Paulo: Cortez, 2006. BRUNER, J. The Ontogenesis of Speech Acts. Journal of Child Language, v. 2, p. 1-19, 1975.

CERTEAU, M. de. A invenção do cotidiano. Petrópolis: Vozes, 1996.

GRAFF, H. The Literacy Myth: Literacy and Social Structure in the $19^{\text {th }}$ Century City. New York: Academic Press, 1979.

KATO, M. No mundo da escrita. Campinas: Ática, 1986.

MARCUSCHI, L. A. Da fala para a escrita: atividades de retextualização. São Paulo: Cortez, 2001a.

MARCUSCHI, L. Letramento e oralidade no contexto das práticas sociais e eventos comunicativos. In: SIGNORINI, I. (Org.). Investigando a relação orall escrito e as teorias do letramento. Campinas: Mercado de Letras, 2001b.

ROJO, R. Letramento escolar, oralidade e escritura em sala de aula: diferentes modalidades ou gêneros do discurso? In: SIGNORINI, I. (Org.). Investigando a relação orallescrito e as teorias do letramento. Campinas: Mercado de Letras, 2001. 
ROJO, R. Atividades de linguagem, jogos de linguagem e gêneros do discurso: a socioconstrução da linguagem oral e escrita. In: . Falando ao pé da letra. São Paulo: Parábola, 2010.

SCHNEUWLY, B.; DOLZ, J. Gêneros orais e escritos na escola. Campinas: Mercado de Letras, 2004.

SOARES, M. Letramento: um tema em três gêneros. Belo Horizonte: Autêntica, 2001.

STREET, B. Literacy in Theory and Practice. Cambridge: Cambridge University Press, 1984.

TERZI, S. A oralidade e a construção da leitura por crianças de meios iletrados. In: KLEIMAN, A. (Org.). Os significados do letramento: uma nova perspectiva sobre a prática social da escrita. Campinas: Mercado de Letras, 1995.

WITTGENSTEIN, L. Investigações filosóficas. São Paulo: Nova Cultural, 1999.

Recebido em 13/03/2012. Aprovado em 16/07/2012. 